\title{
CDISC SDTM Acute Coronary Syndrome Presentation Category Terminology
}

National Cancer Institute

\section{Source}

National Cancer Institute. CDISC SDTM Acute Coronary Syndrome Presentation

Category Terminology. NCI Thesaurus. Code C101865.

Terminology associated with the acute coronary syndrome presentation category codelist of the Clinical Data Interchange Standards Consortium (CDISC) Study Data Tabulation Model (SDT M). 